\title{
Fluoroquinolone antimicrobial drugs
}

\author{
Tiffany Chan MD, Paul E. Bunce MA MD
}

Cite as: CMAJ 2017 May 1;189:E638. doi: 10.1503/cmaj.160938

\section{Fluoroquinolones are antimicrobial drugs with broad-spectrum \\ 1 activity \\ Fluoroquinolones are bactericidal agents that inhibit DNA synthesis in bacte- ria. Early fluoroquinolones (e.g., ciprofloxacin) primarily target gram-negative bacteria, including Pseudomonas species. Newer agents (e.g., levofloxacin and moxifloxacin) have expanded coverage against gram-positive bacteria (e.g., Staphylococcus and Streptococcus species), Mycobacterium species and some anaerobes, but have reduced activity against Pseudomonas species. ${ }^{1}$}

\section{Empirical use of fluoroquinolones for many community-acquired infections is not recommended}

In 2016, the United States Food and Drug Administration advised that the adverse effects of fluoroquinolones outweighed their benefits for the treatment of acute sinusitis and bronchitis, and uncomplicated urinary tract infections. ${ }^{2}$ If fluoroquinolones are used empirically, they should be changed to a narrowerspectrum agent after results for susceptibility testing are available. ${ }^{2}$

\section{Fluoroquinolone use is associated with development of} antimicrobial resistance and therapeutic failure

Resistance to fluoroquinolones is found in up to $34 \%$ of infections due to Neisseria gonorrhoeae in Canada ${ }^{3}$ and in $11 \%$ of urinary infections due to Escherichia coli in North America. ${ }^{4}$ Resistance in isolates of Streptococcus pneumoniae remains low (i.e., about $1.2 \%$ in Canada). ${ }^{3}$ Awareness of local resistance patterns is essential because of the variability in rates across regions.

4

\section{Fluoroquinolones should be prescribed on an individual basis}

Fluoroquinolones should be prescribed only for patients requiring broad spectrum antibiotics who have severe $\beta$-lactam allergies (e.g., anaphylaxis) or require treatment of organisms resistant to first-line agents. Fluoroquinolones offer a convenient and cost-effective option in patients with deep-seated infections (e.g., osteomyelitis and prostatitis) because of their once- or twicedaily dosing and greater than $90 \%$ oral bioavailability. ${ }^{1}$ Consultation with an infectious disease specialist should be considered when prescribing fluoroquinolones for such complicated infections.

\section{Fluoroquinolones may have serious adverse effects}

Severe adverse effects include gastrointestinal complaints (common, up to $10 \%$ of cases), QT prolongation that may cause malignant arrhythmias, tendinopathy, diarrhea associated with Clostridium difficile (uncommon, up to $5 \%$ of cases), dysglycemia, neuropathy and retinal detachment (uncommon, up to $1 \%$ of cases). ${ }^{1,5}$ Fluoroquinolones should not be given in conjunction with calcium supplements, which decrease their bioavailability, or with other QTprolonging agents. ${ }^{1}$

\section{References}

1. Hooper DC. New uses for new and old quinolones and the challenge of resistance. Clin Infect Dis 2000;30:243-54.

2. FDA Drug Safety Communication: FDA advises restricting fluoroquinolone antibiotic use for certain uncomplicated infections; warns about disabling side effects that can occur together. Silver Spring (MD): US Food and Drug Administration, Center for Drug Evaluation and Research; updated 2016. Available: www.fda.gov/Drugs /DrugSafety/ucm500143.htm (accessed 2016 May 27).

3. Canadian Antimicrobial Resistance Surveillance System report 2016. Ottawa: Public Health Agency of Canada; 2016.

4. Karlowsky JA, Hoban DJ, DeCorby MR, et al. Fluoroquinolone-resistant urinary isolates of Escherichia coli from outpatients are frequently multidrug resistant: results from the North American Urinary Tract Infection Collaborative Alliance-Quinolone Resistance Study. Antimicrob Agents Chemother 2006;50:2251-4.

5. Lipsky BA, Baker CA. Fluoroquinolone toxicity profiles: a review focusing on newer agents. Clin Infect Dis 1999; 28:352-64.

\section{Competing interests: None declared.}

This article has been peer reviewed.

Affiliations: Department of Medicine (Chan, Bunce), University of Toronto; Division of Infectious Diseases (Bunce), University Health Network, Toronto, Ont.

Correspondence to: Paul Bunce,Paul.Bunce@ uhn.ca

CMAJ invites submissions to "Five things to know about ..." Submit manuscripts online at http://mc.manuscriptcentral.com/cmaj 